disappearance of kuru as an important episode in our understanding of the risks associated with this type of infectious process. Informing the wider community of these risks may lead to a more helpful debate about the public health policies required to minimize the chances of another BSE epidemic. Books such as this are useful in this context.

Colin L. Masters is in the Department of Pathology, The University of Melbourne, Parkville, Victoria, 3052, Australia.

\section{The making of a biochemist}

\section{Otto Warburgs Beitrag zur}

Atmungstheorie: Das Problem der Sauerstoffaktivierung*

by Petra Werner

Basilisken-Presse: 1996. Pp. 390. DM136

\section{Mikuláśs Teich}

The biochemist Otto Heinrich Warburg (1883-1970) was a name to conjure with in the days before molecular biology. In 1908 he began to investigate - in part with Otto Meyerhof - the respiratory activities of various materials, such as sea-urchin eggs, avian erythrocytes and liver tissue. His experimental results led him to surmise that cellular oxidation was linked to the catalytic activity of iron in cells.

After returning from the First World War, Warburg continued with his studies of respiration using cancerous tissue, and improved the manometric method of gas analysis. His starting point was that cellular respiration was a cyclic reaction. Oxygen combined with iron to produce higher-valency iron, which reacted with oxidizable organic material and in so doing returned to the bivalent state. Warburg might have obtained the idea of the cycle from Meyerhof, who in 1919 and 1920 studied chemical changes occurring in muscle in relation to the work done or the energy liberated as heat. Meyerhof visualized the breakdown of carbohydrate to lactic acid as the anaerobic phase, and the synthesis of carbohydrate as the aerobic phase, of a 'specific carbohydrate cycle'.

Warburg's investigations of artificial iron-containing systems, which were presumed to be analogous to reactions occurring in living cells, satisfied him that iron functions as the oxygen-transferring constituent of a ubiquitous cellular catalyst, which he named Atmungsferment ('respiratory ferment'). He was a most inventive experimenter. Among the artificial systems that he studied were the oxidation of amino acids by haemin charcoal, and the inhibition of oxygen uptake by cyanide and urethane.

${ }^{*}$ Otto Warburg's Contribution to Respiration Theory: The Problem of Oxygen Activation.
In the late 1920s, he looked into the effect of light on the inhibition by carbon monoxide of respiration in living cells. This work encompassed considerations of photochemical processes in terms of quantum chemistry, and the use of the manometer, photoelectric cell and spectroscope. From the shape of the curve obtained by plotting the effectiveness of light against its wavelength, it was possible to deduce the resemblance between the respiratory ferment and haemins. Warburg was awarded the Nobel prize for physiology or medicine in 1931 for his recognition of the haemin-type nature of the respiratory ferment and its underlying principles.

The development of Warburg's theoretical thinking and experimental procedures are ably chronicled in Petra Werner's introductory essay. Her book is the first volume of an edition of Warburg's correspondence deposited in the Berlin-Brandenburg Academy of Sciences. Regrettably, the 143 published letters covering the period 1906 to 1939 include only 14 by Warburg, all of which were to Jacques Loeb. Warburg's early work was strongly influenced by Loeb's book, published in 1906, which dealt with artificial parthenogenesis and the nature of fertilization in thoroughly physicochemical, reductionist terms. Loeb immediately recognized in Warburg a kindred spirit, and was prepared to get him a grant from the Rockefeller Institute to work in his laboratory, and to help him settle in the United States. Before and after the First World War, Loeb - an early emigré from Germany as a result of his experiences of anti-Semitism in the academic world - befriended not only Warburg, but also Meyerhof and Leonor Michaelis, who contributed to the development of a mathematical theory of enzyme processes. This emerges from Loeb's letters to the two scientists, which are also included in the book.

Outstanding as Warburg was as a scientist, even his admiring Nobel prize-winning research students, Hans Krebs and Hugo Theorell, realized that he tended to pettiness. There can be little doubt that this fuelled his resentment of Meyerhof, who, with Archibald Vivian Hill, won the Nobel prize for physiology or medicine nine years before Warburg for work on muscle metabolism. Werner also refers to Warburg's selective approach to history in two retrospective monographs: "he cited only Nobel prize winners or widely known persons... and left others out; thus, later he never mentioned the name of Jacques Loeb. This retrospective account submerged historical reality beneath an embellished, teleological presentation."

The English version of Warburg's first publication appeared as Heavy Metal Prosthetic Groups and Enzyme Action (Oxford University Press, 1949) and was critically reviewed by David Keilin (Nature 165, 4-5;

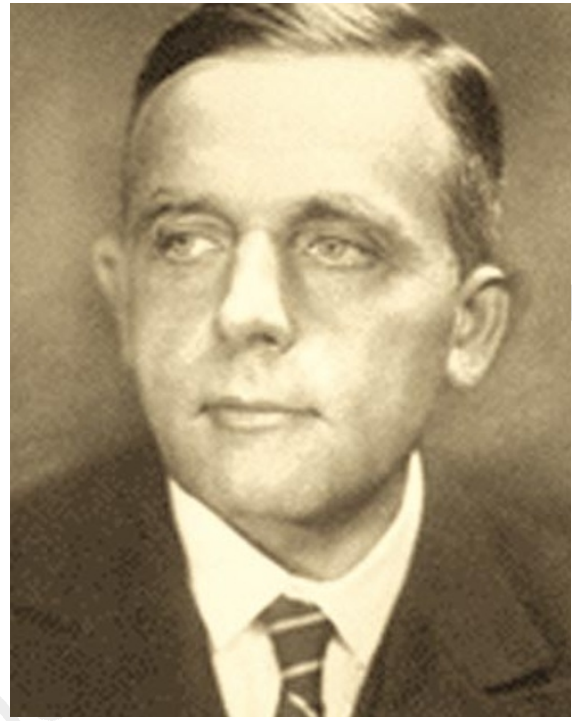

Brilliant but flawed: Warburg tended to pettiness.

1950). In 1925, Keilin demonstrated the reversible oxidation and reduction of a pigment, which he named 'cytochrome', in the thoracic muscles of the adult fly Gasterophilus intestinalis. This was a crucial event in the history of biological oxidation and helped lead to the interpretation of cell respiration in terms of a sequence of reactions driven by oxidation and reduction (the 'respiratory chain'). That Keilin's achievement did not earn him a Nobel prize was, I think, a notable omission. It is unfortunate that his name crops up just once in the book.

That said, the book is an important source for studying the development of the chemistry of life from about 1900 to 1930 . $\square$ Mikulás̆ Teich is at Robinson College, University of Cambridge, Cambridge CB3 9AN, UK.

\section{Software reviews at www.nature.com}

From this week, Nature's website presents comparative reviews of scientific software.

Nature has recruited a group of reviewers to test a wide range of scientific software, including graph-making and statistics packages, mathematics software, systems for bibliography and reference management, and more. This week, Sharon Kardia of the University of Michigan inaugurates the series at www.nature.com, with reviews of 16 graph-making packages.

Kardia explains the criteria used to evaluate the packages, and outlines the strengths and weaknesses of each. She calls attention to unique features, and suggests who might benefit from using each package. A table of system functions shows which packages possess which capabilities, and gives performance ratings for each package, for each of these functions. Each review is hyperlinked to additional product details provided by the manufacturer. 